\title{
Comparison of Demographic Profile, Laboratory, Epidemiology and Clinical Outcomes in Patients with Native Valve and Prosthetic Valve Endocarditis
}

\author{
Hulya Yilmaz Ak, ${ }^{1}$ Yasemin Ozsahin, ${ }^{1}$ Mehmet Ali Yesiltas, ${ }^{2}$ Ismail Haberal, ${ }^{3}$ Serkan Kahraman, ${ }^{4}$ \\ Dogac Oksen, ${ }^{5}$ Mustafa Yildiz ${ }^{6}$ \\ ${ }^{1}$ Istanbul University-Cerrahpasa, Cardiology Institute, Department of Anesthesiology and Reanimation, Istanbul, Turkey; ${ }^{2}$ Istanbul \\ Bakirkoy Dr. Sadi Konuk Training and Research Hospital, Department of Cardiovascular Surgery, Istanbul, Turkey; ${ }^{3}$ Istanbul University- \\ Cerrahpasa, Cardiology Institute, Department of Cardiovascular Surgery, Istanbul, Turkey; ${ }^{4}$ University of Health Sciences Istanbul \\ Mehmet Akif Ersoy Thoracic and Cardiovascular Surgery Training and Research Hospital, Department of Cardiovascular Surgery, \\ Istanbul, Turkey; ${ }^{5}$ Siirt Kurtalan State Hospital, Department of Cardiology, Siirt, Turkey; ${ }^{\circ}$ Istanbul University-Cerrahpasa, Cardiology \\ Institute, Department of Cardiology, Istanbul, Turkey
}

\section{ABSTRACT}

Background: Infective endocarditis (IE) is a heterogenous infection that affects the endothelial surface of the intracardiac structures and other implanted intracardiac devices. We aimed to compare demographical characteristics, causative microorganisms, treatment, and prognosis of prosthetic and native valve endocarditis diagnosed in two separate hospitals.

Material and methods: Between 2010 and 2020, patients admitted with the diagnosis of IE were retrospectively included in our multicenter study. Patients' demographic and epidemiological data, clinical characteristics, infected intracardiac structure and sort of valve, culprit microorganisms, laboratory findings, treatment manifestations and in-hospital outcomes with a period of 6 months were obtained from an electronic medical record system.

Results: A total of 173 consecutive patients had diagnosed IE, $60.1 \%$ (104 patients) of them native valve endocarditis (NVE) and $39.8 \%$ (69 patients) of them prosthetic valve endocarditis (PVE). Baseline demographic properties were not different except hypertension and atrial fibrillation. Patients with prior hypertension were $25 \%$ (26 patients) in NVE; 39.1\% (27 patients) in PVE and the difference was statistically significant. Septic shock was significantly higher in the PVE group than the NVE group (7.4\% versus $1 \%$; $P=.036)$, and also recurrent endocarditis occurred more frequently in the PVE group than the NVE group $(8.8 \%$ versus $1 \% ; P=.016)$.

Conclusion: In our study, although we detected higher mean age, HT, RDW and atrial fibrillation rates compared with NVE, we did not detect a significant difference in mortality and morbidity.

Received February 19, 2021; accepted March 26, 2021.

Correspondence: Mebmet Ali Yesiltas, Consultant, Department of Cardiovascular Surgery S.B.Ü. Bakırköy Dr.Sadi Konuk E.A.H., Zuburatbaba Mah. Dr. Tevfik Sağlam Cad., No:11; +90-212-4147171; fax: +90 (212) 414-64-94 (e-mail:dr.maliyes@gmail.com).

\section{INTRODUCTION}

Infective endocarditis (IE) is a heterogenous infection that affects the endothelial surface of the intracardiac structures and other implanted intracardiac devices. Despite significant improvements in the diagnosis and treatment of IE, in-hospital mortality rates are approaching nearly 15\% [Bor 2013].

The incidence in prospective studies of developed countries was determined 3-10/100000 per year and remained constant for years [Leone 2012]. The risk factors and predisposing conditions progressively have changed in recent years. More specifically, the causative infectious agents especially Staphylococcus aureus, which is acquired from medical interventions, are on an increasing trend [Selton-Suty 2012]. In industrialized countries, as a consequence of aging population and increasing comorbidities, the incidence of rheumatic valvular disease has decreased, while the incidence of prosthetic valve and intracardiac device endocarditis consistently is increasing [Şimşek-Yavuz 2019]. Furthermore, the increased number of immunocompromised patients and individuals using intravenous drugs has modified the epidemiological characteristics of patients over the years. With the advancement in microbiology laboratories, new microorganisms like Coxiella burnetii, Brucella, Bartonella, Tropheryma whipplei and fungi recently have been described as rare but fatal pathogens [Loupa 2004]. Advancement of echocardiography devices and description of modified Duke criteria have facilitated and enhanced the accuracy of diagnosis [Gomes 2017].

Prosthetic valve endocarditis (PVE) is more demanding to certainly diagnose, therefore prognosis of PVE is worse than native valve endocarditis (NVE). Transthoracic echocardiography (TTE) in prosthetic valves, especially in mechanical valves is more complicated both in performing and interpreting because of the shields and artifacts of stiff substances [Zoghbi 2010]. The difficulties of diagnosis bring higher mortality rates in PVE, due to delay of certain diagnosis and the prognosis is getting worse since the diagnosis continues to delay [Schulz 1996]. Because of the closer anatomical distance between the esophagus and cardiac structures (i.e., mitral and tricuspid valve), the widespread usage of transesophageal 
Table 1. Demographic data

\begin{tabular}{|c|c|c|c|c|}
\hline Age & $57(42.5-66)$ & $55(42-64)$ & $61(45-71)$ & .036 \\
\hline Substance abuse & $5(2.9)$ & $4(3.8)$ & $1(1.4)$ & .336 \\
\hline DM & $27(15.6)$ & $16(15.4)$ & $11(15.9)$ & .921 \\
\hline CAD & $38(22.0)$ & $21(20.2)$ & $17(24.6)$ & .614 \\
\hline $\mathrm{CHF}$ & $28(16.2)$ & $16(15.4)$ & $12(17.4)$ & .889 \\
\hline $\mathrm{AF}$ & $26(15.0)$ & $9(8.7)$ & $17(24.6)$ & .008 \\
\hline PM-ICD-CRT-D (P) & $13(7.5)$ & $5(4.8)$ & $8(11.6)$ & .173 \\
\hline CRF & $25(14.5)$ & $17(16.3)$ & $8(11.6)$ & .516 \\
\hline Immunosuppressive disease & $3(1.7)$ & $3(2.9)$ & $0(0)$ & .215 \\
\hline Cyanotic congenital heart disease & $3(1.7)$ & $1(1.0)$ & $2(2.9)$ & .344 \\
\hline Noncyanotic congenital heart disease & $1(0.6)$ & $1(1.0)$ & $0(0)$ & .601 \\
\hline
\end{tabular}

DM, diabetes mellitus; $\mathrm{HT}$, hypertension; CAD, coronary artery disease; CHF, chronic heart failure; AF, atrial fibrillation; PM, pacemaker; ICD, implantable cardioverter defibrillator; CRT-D (P), cardiac resynchronization therapy defibrillator (pacemaker); CRF, chronic renal failure; COPD, chronic obstructive pulmonary disease

echocardiography (TEE) improves the imaging of prosthetic valves refraining from undesired acoustic shadows and artifacts. The common application of TEE markedly improves the diagnosis of PVE. However, the studies comparatively establishing the clinical manifestations and outcomes of PVE and NVE are limited. We aimed to compare demographical characteristics, causative microorganisms, treatment, and prognosis of PVE and NVE with those diagnosed in two separate hospitals.

\section{METHODS}

Study population: Between January 2010 and January 2020, patients admitted with the diagnosis of IE retrospectively were included in our multicenter study. The modified Duke diagnostic criteria, which was mentioned in the latest guidelines of the European Society of Cardiology, was used to achieve a certain diagnosis and uncertain cases were excluded from the analysis of the study [Horstkotte 2004; Li 2000]. Patients' demographic and epidemiological data, clinical characteristics, infected intracardiac structure and sort of valve, culprit microorganisms, laboratory findings, treatment manifestations, and in-hospital outcomes with a period of 6 months were obtained from an electronic medical record system. Mortality, cerebrovascular accident, septic shock, renal failure, and arrhythmia were considered outcomes. All the treatments were performed, in accordance with relevant guidelines of The European Society of Cardiology [Habib 2015].
Patients were separated into two groups, according to valve structure whether native or prosthetic valve (mechanical and bioprosthesis valve). The following variables were recorded for each patient: Patient demographic, comorbid condition, prior congestive heart failure, valvular heart disease, cardiac valve operation, prosthetic valve, pacemaker implantation, intravenous drug usage, microbiological results, echocardiographic findings, treatment manifestations, and adverse outcomes. Septic pulmonary infarcts, major arterial emboli, mycotic aneurysms, intracranial bleeding, conjunctival bleeding, and Janeway lesions were defined as vascular phenomenon and immunological phenomena were glomerulonephritis, Osler's nodes, Roth spots, or positive rheumatoid factor. Routine laboratory findings included blood glucose, blood urea nitrogen, serum creatinine, C-reactive protein (CRP), alanine aminotransferase (ALT), rheumatoid factor, hemoglobin level, platelet and white blood cell (WBC) counts, and erythrocyte sedimentation rate (ESR) at the time of diagnosis. Three samples of blood culture were obtained at admission to the hospital from different venipuncture sites with at least one-hour intervals. Each collected set included one aerobic and one anaerobic bottle. In case of any specific analyses like polymerase chain reaction, Wright agglutination test and other serological tests were performed, and the results of tests also were recorded. All patients were evaluated with TTE and/or TEE within 24 hours of admission. All the echocardiographies were performed by Vivid 5 (GE, Horten, Norway) or Epic 7 (Philips, Amsterdam, Netherlands) and diameters, valve functions and morphology, left ventricular 
Table 2. Signs and symptoms of infective endocarditis

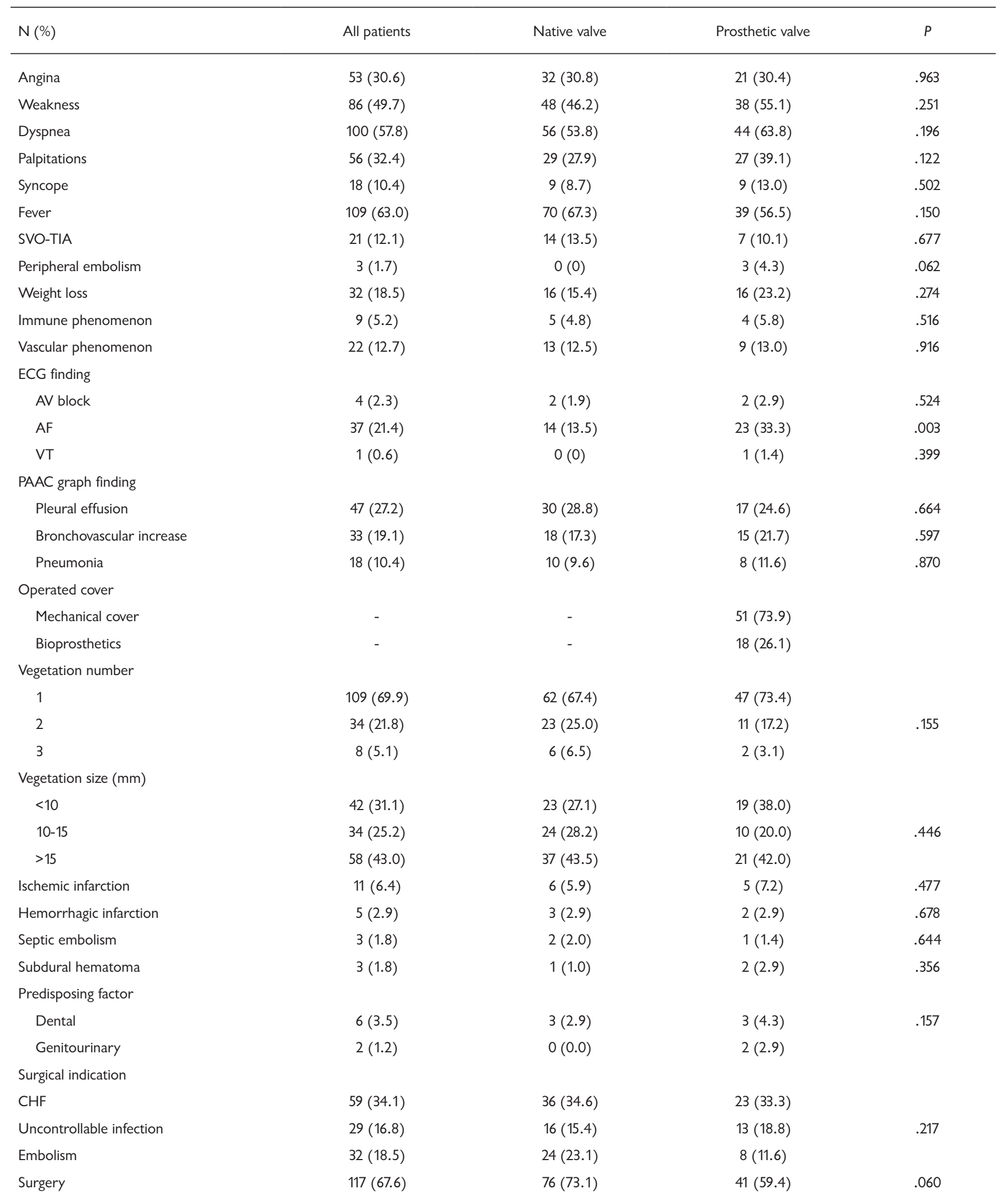


Table 2. Signs and symptoms of infective endocarditis [CONT.]

\begin{tabular}{lccc}
\hline $\mathrm{N}(\%)$ & All patients & Native valve & Prosthetic valve \\
\hline How many days after surgery & $16(9.75-30)$ & $16(10-26)$ & $21(9-38)$ \\
Pre-procedural antibiotic & $4(2.3)$ & $1(1.0)$ & $3(4.3)$ \\
\hline
\end{tabular}

CV, cerebrovascular event; TIA, transient ischemic attack; ECG, electrocardiogram; AV block, atrioventicular block; AF, atrial fibrillation; VT, ventricular fibrillation; PAAC, posteroanterior chest radiography; CHF, chronic heart failure

Table 3. Initial laboratory findings of infective endocarditis patients

\begin{tabular}{|c|c|c|c|c|}
\hline $\mathrm{Hb}$ & $10.86 \pm 1.80$ & $10.95 \pm 1.88$ & $10.38 \pm 2.19$ & .069 \\
\hline WBC & $10.8(8.0-14.2)$ & $10.42(7.93-14.0)$ & $11.14(8.10-16.0)$ & .343 \\
\hline Neutrophil & $8.1(5.5-11.7)$ & $8.06(5.33-10.97)$ & $8.53(5.6-12.63)$ & .189 \\
\hline Monocyte & $0.77(0.57-0.95)$ & $0.7(1.16-2.2)$ & $1.47(1.0-1.9)$ & .001 \\
\hline Platelet & $255 \pm 78.6$ & $262.4 \pm 104.8$ & $244.3 \pm 107.8$ & .271 \\
\hline MPV & $9.5(7.9-10.6)$ & $9.4(7.9-10.6)$ & $9.7(8.3-10.9)$ & .285 \\
\hline CRP & $74.1(31.5-127.0)$ & $72.73(26.75-114.0)$ & $81.1(35.0-155.0)$ & .102 \\
\hline RDW & $15.3(13.6-17.1)$ & $14.9(13.5-16.1)$ & $16.0(14.1-18.3)$ & .011 \\
\hline K & $4.2(3.8-4.6)$ & $4.4(3.9-4.7)$ & $4.2(3.7-4.6)$ & .155 \\
\hline $\mathrm{Ca}$ & $8.4 \pm 0.57$ & $8.55 \pm 0.74$ & $8.57 \pm 0.67$ & .845 \\
\hline ALT & $18(12-28.5)$ & $19(13-26.5)$ & $16(10-32)$ & .162 \\
\hline AST & $22(16-35)$ & $20(16-33)$ & $24(14-37)$ & .582 \\
\hline
\end{tabular}

$\mathrm{Hb}$, hemoglobin; Htc, hematocrit; WBC, white blood cell; MPV, mean platelet volume; CRP, C-reactive protein; RDW, red cell distribution width; ALT, Alanine aminotransferase; AST, Aspartate aminotransferase

functions, and intracardiac IE complications (i.e., vegetations, perivalvular abscess, leaflet perforation, paravalvular regurgitation and prosthetic valve dehiscence) were evaluated. Left ventricular ejection fraction was calculated by modified Simpson method and valvular stenosis diagnosed by continuous wave and pulse valve Doppler imaging, according to current guidelines [Lancellotti 2010]. The study was approved by the local ethics committee and conformed to ethical norms and Declaration of Helsinki for human research.

Statistical analysis: The data were presented as mean \pm standard deviation and median (25th-75th percentiles) values for continuous variables, as percentage and number of cases for categorical variables. Normal distribution was tested with the Kolmogorov-Smirnov test. Unpaired t test was used to test the difference between the two group continuous variants, which showed normal distribution. Two-group non-parametric comparisons were calculated by the MannWhitney U test when non-normally distributed. Pearson's Chi-square, Fisher's exact tests were performed to test the categorical variants. The significance level was considered $P<$ .05 . All statistical analyses were performed using the statistical package for social science of SPSS software version 23.0 (SPSS Inc., Chicago, IL, USA).

\section{RESULTS}

A total of 173 consecutive patients had diagnosed IE, $60.1 \%$ (104 patients) of them NVE and 39.8\% (69 patients) of them PVE. The mean age of NVE was 55 (42-64), and PVE was 61 (45-71). The mean age of patients suffering from PVE was significantly higher than NVE $(P=.036)$. 
Table 4. Transesophageal echocardiography findings of the patients

\begin{tabular}{|c|c|c|c|c|}
\hline Aortic veg. & $70(43.5)$ & $47(49.5)$ & $23(34.8)$ & .093 \\
\hline Tricuspid veg. & $5(3.1)$ & $3(3.2)$ & $2(3.0)$ & .667 \\
\hline Pulmonary veg. & $1(0.6)$ & $0(0)$ & $1(1.5)$ & .410 \\
\hline Abscess & $22(13.6)$ & $11(11.6)$ & $11(16.4)$ & .514 \\
\hline Fistula & $7(4.3)$ & $3(3.2)$ & $4(6.0)$ & .313 \\
\hline Perforation & $25(15.4)$ & $21(22.1)$ & $4(6.0)$ & .004 \\
\hline Pseudoaneurysm & $7(4.3)$ & $2(2.1)$ & $5(7.5)$ & .105 \\
\hline Paravalvular leak & $15(9.3)$ & $0(0)$ & $15(22.4)$ & $<.001$ \\
\hline Mitral & $12(7.0-17.0)$ & $12.75(7.5-18)$ & $9.0(5.0-15.0)$ & .063 \\
\hline
\end{tabular}

Table 5. Culture and causative microorganisms

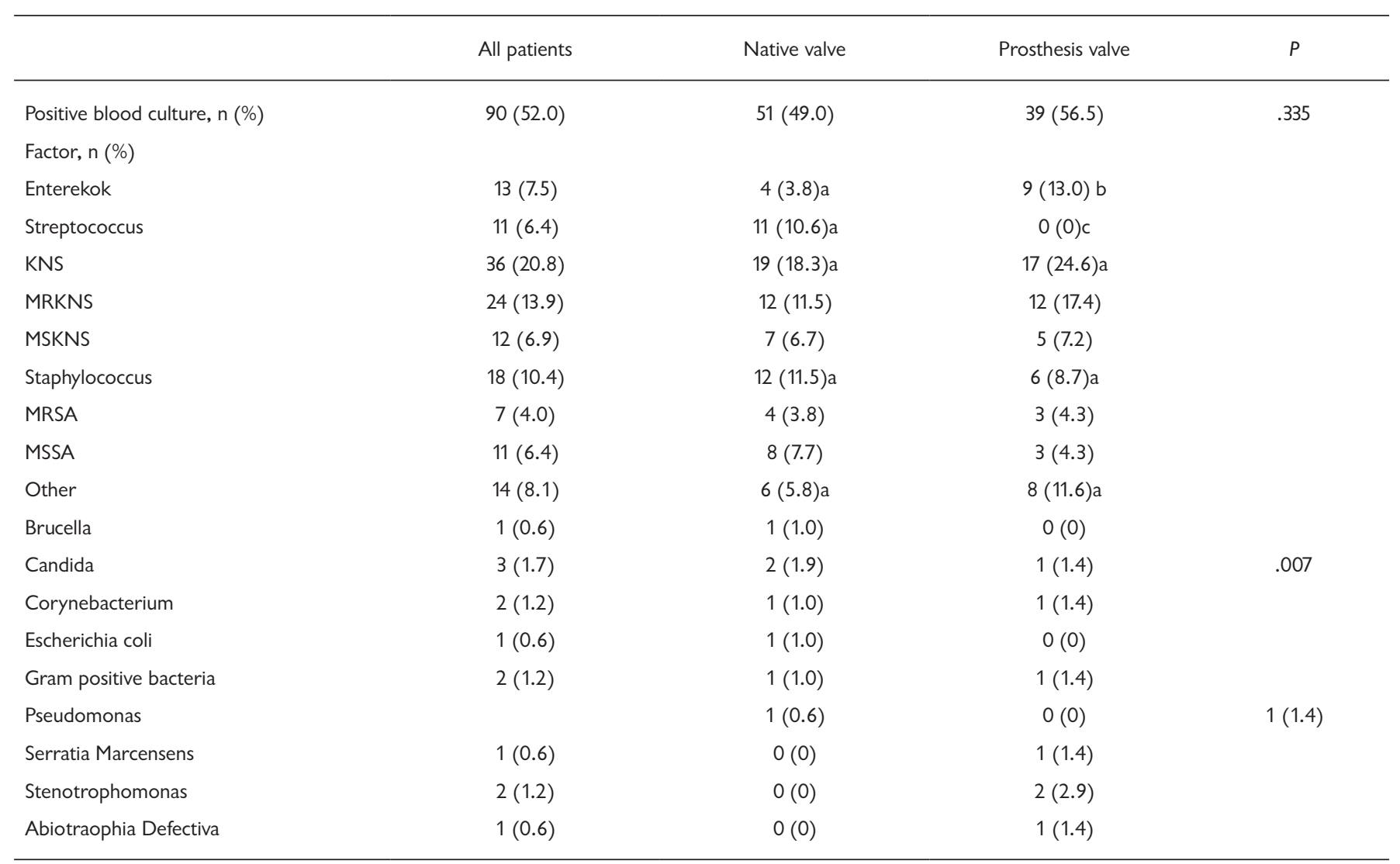

CNS, Coagulase-negative staphylococcus; MSCNS, Methicillin-sensitive coagulase-negative staphylococcus; MRCNS: Methicillin-resistant coagulase-negative staphylococcus; MRSA, Methicillin-sensitive staphylococcus aureus; MSSA, Methicillin-resistant staphylococcus aureus 
Table 6. Comparison of patients according to medical and surgical treatment

\begin{tabular}{|c|c|c|c|}
\hline & $\begin{array}{l}\text { Medically treated } \\
\qquad(\mathrm{N}=56)\end{array}$ & $\begin{array}{l}\text { Surgically treated } \\
\qquad(N=117)\end{array}$ & $P$ \\
\hline Age & $58 \pm 16$ & $52 \pm 15$ & .016 \\
\hline Gender (women), n (\%) & $24(57.1)$ & $34(29.1)$ & .072 \\
\hline DM, n (\%) & $16(28.6)$ & $11(9.4)$ & .001 \\
\hline HT, n (\%) & $26(46.4)$ & $27(23.1)$ & .002 \\
\hline CAD, n (\%) & $17(30.4)$ & $21(17.9)$ & .065 \\
\hline $\mathrm{CHF}, \mathrm{n}(\%)$ & $14(25.0)$ & $14(12.0)$ & .029 \\
\hline AF, n (\%) & $11(19.6)$ & $15(12.8)$ & .240 \\
\hline \multicolumn{4}{|l|}{ Clinical complications, n (\%) } \\
\hline Heart failure & $5(9.1)$ & $8(6.8)$ & .404 \\
\hline Renal failure & $8(14.5)$ & $12(10.3)$ & .413 \\
\hline CVA-TIA & $5(9.1)$ & $2(1.7)$ & .035 \\
\hline Intracerebral bleeding & $3(5.5)$ & $2(1.7)$ & .187 \\
\hline Peripheral embolism & $2(3.6)$ & $3(2.6)$ & .514 \\
\hline Osteomyelitis & $1(1.8)$ & $0(0)$ & .320 \\
\hline $\begin{array}{l}\text { Rhythm conduction } \\
\text { disorder }\end{array}$ & $2(3.6)$ & $11(9.4)$ & .152 \\
\hline Septic shock & $3(5.5)$ & $3(2.6)$ & .291 \\
\hline Pericarditis-myocarditis & $1(1.8)$ & $1(0.9)$ & .539 \\
\hline GIS bleeding & $2(3.6)$ & $0(0)$ & .101 \\
\hline Re-endocarditis & $4(7.3)$ & $3(2.6)$ & .148 \\
\hline In-hospital death & $17(30.9)$ & $20(17.1)$ & .040 \\
\hline
\end{tabular}

DM, diabetes mellitus; $\mathrm{HT}$, hypertension; $\mathrm{CHF}$, chronic heart failure; $\mathrm{CAD}$, coronary artery disease; $\mathrm{AF}$, atrial fibrillation; CVA, cerebrovascular accident; TIA, trans ischemic attack; GIS, gastrointestinal system

Male patients accounted for $72.1 \%$ (75 patients) in the NVE group and 58\% (40 patients) in the PVE group. There was no statistically significant gender difference between the groups. The mean duration of hospital stay was shorter in the NVE group than the PVE group (31 days (18-44) versus 40 days (24-50); $P=.053$, respectively). The median duration of intensive care unit stay time was similar in the two groups (4 days (2-9) versus 4 days $(2-10) ; P=.821$, respectively). Table 1 shows the differences between NVE and PVE, regarding demographic, clinic and echocardiographic findings (Table 1). Baseline demographic properties were not different, with the exception of hypertension (HT) and atrial fibrillation (AF). Patients with prior HT were $25 \%$ (26 patients) in NVE; 39.1\% (27 patients) in PVE, and the difference was statistically significant. AF rates were found significantly higher in PVE cases than NVE cases $(8.7 \%$ versus $24.6 \%$; $\mathrm{P}=0.008$, respectively). In the NVE and PVE groups, the number of implantable intracardiac device rates were $4.8 \%$ (five patients) and $11.6 \%$ (eight patients), respectively. The NVE group contained three congenital heart disease patients
Table 7. Comparison of native and prosthetic valve endocarditis undergoing surgical treatment

\begin{tabular}{|c|c|c|c|}
\hline Surgical group $(N=117)$ & $\begin{array}{l}\text { Native valve } \\
(\mathrm{N}=76)\end{array}$ & $\begin{array}{l}\text { Prosthetic valve } \\
\qquad(\mathrm{N}=41)\end{array}$ & $P$ \\
\hline Age & $51 \pm 14$ & $55 \pm 15$ & .181 \\
\hline Gender (women), n (\%) & $18(23.7)$ & $16(39.0)$ & .081 \\
\hline DM, n (\%) & $8(10.5)$ & $3(7.3)$ & .418 \\
\hline HT, n (\%) & $17(22.4)$ & $10(24.4)$ & .804 \\
\hline CAD, n (\%) & $13(17.1)$ & $8(19.5)$ & .746 \\
\hline $\mathrm{CHF}, \mathrm{n}(\%)$ & $9(11.8)$ & $5(12.2)$ & .587 \\
\hline $\mathrm{AF}, \mathrm{n}(\%)$ & $7(9.2)$ & $8(19.5)$ & .112 \\
\hline \multicolumn{4}{|l|}{ Clinical complications, n (\%) } \\
\hline Heart failure & $4(5.3)$ & $4(9.8)$ & .289 \\
\hline Renal failure & $9(11.8)$ & $3(7.3)$ & .335 \\
\hline CVA-TIA & $1(1.3)$ & $1(2.4)$ & .580 \\
\hline Intracerebral bleeding & $1(1.3)$ & $1(2.4)$ & .580 \\
\hline Peripheral embolism & $2(2.6)$ & $1(2.4)$ & .719 \\
\hline Osteomyelitis & $0(0)$ & $0(0)$ & \\
\hline Rhythm conduction disorder & $8(10.5)$ & $3(7.3)$ & .418 \\
\hline Septic shock & $0(0)$ & $3(7.3)$ & .041 \\
\hline Pericarditis-myocarditis & $1(1.3)$ & $0(0)$ & .650 \\
\hline GIS bleeding & $0(0)$ & $0(0)$ & \\
\hline Re-endocarditis & $1(1.3)$ & $2(4.9)$ & .281 \\
\hline In-hospital death & $10(13.2)$ & $10(24.4)$ & .124 \\
\hline
\end{tabular}

DM, diabetes mellitus; $\mathrm{HT}$, hypertension; $\mathrm{CHF}$, chronic heart failure; $\mathrm{CAD}$, coronary artery disease; $\mathrm{AF}$, atrial fibrillation; CVA, cerebrovascular accident; TIA, trans ischemic attack; GIS, gastrointestinal system

(one atrial septal defect, one ventricular septal defect, and one subaortic membrane). Five congenital heart disease patients were in the PVE group, including one patent ductus arteriosus, one ventricular septal defect, one patent foramen ovale, one transposition of the great arteries with pulmonary stenosis, and one Tetralogy of Fallot. Fifty-one patients (73.9\%) had mechanical valve and 18 patients $(26.1 \%)$ had bioprosthesis valve in the PVE group.

The symptoms were non-specific and demonstrated in Table 2. The most frequent symptom of the NVE group at admission was fewer (67.3\%) and in the PVE group was dyspnea $(63.8 \%)$. Congestive heart failure symptoms at admission were $53.8 \%$ and $63.8 \%$, respectively, in the NVE and PVE groups $(P=.196)$. The symptoms at admission were not significant. Immunological phenomena were found in $4.8 \%$ (five patients) and $5.8 \%$ (four patients) in the NVE and PVE groups, respectively, and not significant $(P=.516)$. Vascular phenomena were found $12.5 \%$ (13 patients) and $13 \%$ (nine patients) in the NVE and PVE groups and not statistically significant $(P=.916)$. In the NVE and PVE groups, laboratory parameters were listed in Table 3 and not statistically 
Table 8. Clinical complications in patients with infective endocarditis

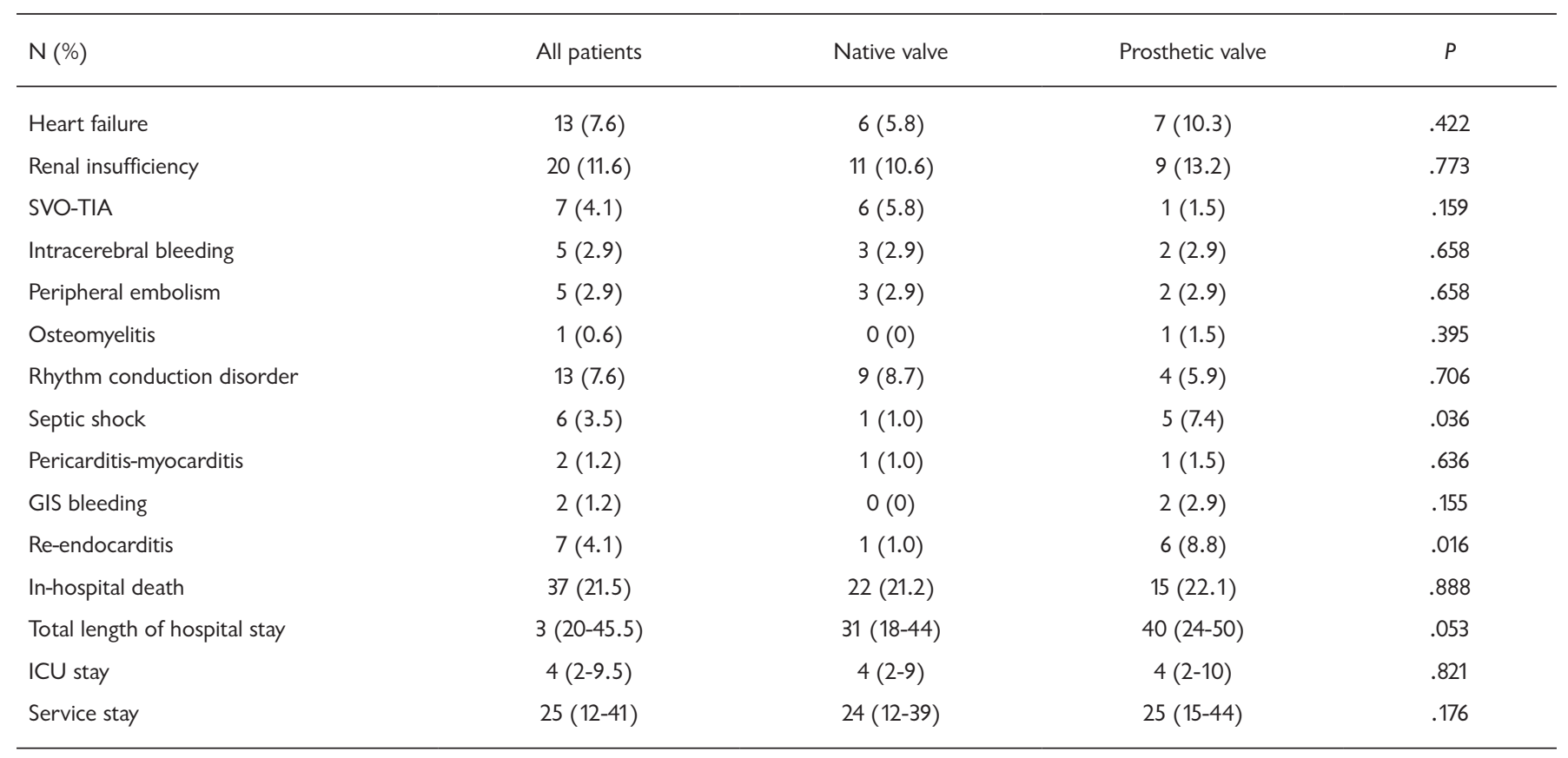

GIS, gastrointestinal system; SVO, cerebrovascular accident; TIA, transient ischemic attack; ICU, intensive care unit

significant between the two groups, except monocyte and red cell distribution width (RDW) (Table 3). In the NVE and PVE groups, the mean monocyte count was 0.7 (1.16$2.2)$ and $1.47(1.0-1.9)$, respectively, and there was a statistically significant difference $(P=.001)$. Also, RDW was significantly higher in the PVE group with a mean value of 14.9 (13.5-16.1) compared with the NVE group with a mean value of $16.0(14.1-18.3)(P=.011)$. In our study, while the rate of mitral regurgitation was significantly higher in NVE $(P<.001)$, among echocardiography findings, no difference was found between the two groups in other findings. In terms of TEE findings, the valve perforation was significantly higher in NVE $(P=.004)$ (Table 4). Coagulase negative staphylococcus (CNS) was the most common pathogen in both groups (20.8\%). Staphylococcus aureus (S. aureus) was significantly higher in NVE (11.5) compared with PVE (8.7) $(P=.007)$ (Table 5).

Management and clinical outcomes: All patients received treatment regimes, including antibiotics according to IE guidelines of the European Society of Cardiology [Habib 2015]. Seventy-six patients (73.1\%) with NVE and 41 patients $(59.4 \%)$ with PVE underwent cardiac surgery $(P=$ $.06)$. The median delay time to surgery was 16 days (10-26) and 21 days (9-38) in the NVE and PVE groups respectively, also not statistically significant $(P=.236)$. In the NVE and PVE groups, patients underwent surgery as a consequence of severe CHF (34.6\% and 33.3\%), persistent infection despite adequate antibiotic therapy (15.4\% and $18.8 \%)$, and recurrent systemic embolization (23.1\% and $11.6 \%$ ), respectively. In addition, endocarditis patients were examined, according to medical and surgical treatment by performing additional analyses in our study (Table 6). Patients with natural and prosthetic valve endocarditis who underwent surgical treatment were compared (Table 7).

During their hospital stay, $21.2 \%$ (22 patients) of the NVE patients and $22.1 \%$ (15 patients) of the PVE patients died $(P=.888)$. CHF (NYHA class III and IV) developed in 5.8\% (six patients) of the NVE group and $10.3 \%$ (seven patients) with PVE $(P=.422)$. In the PVE and NVE groups, peripheral embolization rates were similar $(2.9 \%$ versus $2.9 \% ; P=$ .658). Septic shock was significantly higher in the PVE group than the NVE group $(7.4 \%$ versus $1 \% ; P=.036)$ and recurrent endocarditis occurred more frequently in the PVE group than the NVE group $(8.8 \%$ versus $1 \% ; P=.016)$. Cerebrovascular accidents in PVE in-hospital mortality rate were similar in surgically and non-surgically treated patients $(21 \%$ versus $17 \%)$. In NVE, patients had a lower rate of cerebrovascular accidents than patients with PVE, but it was not statistically significant $(8.6 \%$ versus $4.3 \% ; P=.155)$ (Table 8$)$.

\section{DISCUSSION}

This study was a retrospective cohort that included patients from a tertiary care center in Turkey. Despite the advancement in diagnosis and treatment, still $15-30 \%$ hospital mortality rates were reported in recent studies [Nunes 2010]. According to studies, PVE accounts for $20 \%$ of overall IE cases and is associated with worse outcomes [Cahill 2016]. The challenge of PVE initiates from diagnosis as the acoustic shadowing and reverberations significantly affect imaging and can cause delays. In our study, we can attribute the high rate of 
PVE (39.8\%) compared with similar studies to the improvements in image quality of TEE devices, which recently have been developed with the advancement of technology. In our study, the similarity between PVE and NVE in-hospital mortality rate can be associated with the advances in diagnosis.

Due to the high prevalence of rheumatic valve disease in our country, in our cohort, patients with NVE tend to be younger than patients with PVE [Tuğcu 2009]. According to studies from developed countries, the mean age gradually was higher than our cohort, which arises from the increased rate of implanted cardiac devices and high rate of degenerative valves [Nunes 2010; Durante-Mangoni 2008]. Although the average age of patients with IE has increased over the years, IE still is affecting the younger population in our country. With the increase in the average life expectancy and interventions for older patients, such as cardiac devices and transcatheter aortic valve implantation (TAVI), it is certain that the mean age of patients with IE tends to increase in the near future. In addition, in our cohort, the rate of $\mathrm{HT}$ and $\mathrm{AF}$ was higher in patients with PVE. We consider this a result of the higher mean age of PVE patients.

The most common microorganisms causing IE both in our country and in the world are S. aureus, streptococcus, CNS and enterococcus, respectively [Baddour 2015]. In addition, Brucella ranks 5th among the most common pathogens in our country [Şimşek-Yavuz 2019]. It was shown by Murdoch et al that pathogens in IE etiology show regional differences. While the most common pathogen in Europe and North America was S. aureus, the most common pathogen in South America was streptococcus. Briefly, CNS is the main pathogen in our cohort both in NVE and PVE patients. Among the NVE patients, S. aureus is more frequent than PVE patients [Murdoch 2009].

Despite the advances in diagnosis, treatment and surgery in the last century, the mortality rate has not decreased. In early reports, in-hospital mortality of patients with PVE mentioned about $17 \%$, whereas in the NVE group $21 \%$ patients died in hospital [Schulz 1996]. Leone et al reported 12.3\% and 23.8\% in-hospital mortality in patients with NVE and PVE, respectively [Leone 2012]. In a recent study by Marques et al, they found the mortality rate to be $31.3 \%$. It is noteworthy the increase in mortality rate over time. In our study, the inhospital mortality rate was $21.5 \%$ [Erbay 2010]. Many prognostic factors have been identified to predict mortality in hospital. So far, S. aureus endocarditis, cerebral hemorrhage and embolism, renal failure, septic shock, involvement of multiple valves, previous IE, and bigger vegetation size were independent predictors for in-hospital mortality reported in previous studies [Hasbun 2003]. A few studies showed that associated heart failure, periannular complications, and staphylococcus aureus infection is related to poor prognosis [Granowitz 2003; Marques 2020; San Román 2007]. A study showed that the combination of all these three criteria causes the need for surgery and mortality up to $79 \%$ [San Román 2007]. These criteria mentioned above as risk factors for mortality also are considered a surgery indication and significantly affect postoperative outcomes. However, the mortality predictors, such as vegetation size and number, cerebrovascular accidents were more often in the PVE group. In our cohort, this nonstatistically significant difference did not affect in-hospital mortality rates between patients with NVE and PVE.

Septic shock is a serious complication with poor prognosis and high mortality in patients with IE [Habib 2015; San Román 2007; Werdan 2014]. Another important finding of our study was that the rate of septic shock in patients with PVE was significantly higher than in patients with NVE. However, this complication did not affect the hospital and ICU stay or in-hospital mortality among the groups. In the study by Alonso-Valle et al, in which they evaluated PVE patients, they determined the most common cause of in-hospital mortality as septic shock. In the study of Olmos et al., it was shown that the presence of diabetes, acute renal failure, S. aureus infection, supraventricular tachycardia, vegetation size $(15 \mathrm{~mm})$ and persistent signs of infection in patients with IE were associated with the development of SS [Olmos 2013]. However, this study did not distinguish prosthetic and native valves. In our study, these findings were at similar rates in both prosthetic and natural valves. Also, despite the previous studies, although the $S$. aureus endocarditis is less common in prosthetic valves, septic shock rate was found higher in prosthetic valves in our study. We believe that the relationship between septic shock and PVE should be examined in more detailed studies.

Knowing the prognosis of patients forces clinicians to consider possible complications that a patient may encounter and makes us think of and be prepared for the future. It is difficult to talk about a definite prognosis for IE, which has difficulties in diagnosis and treatment. From laboratory findings, thrombocytopenia is common in IE patients, and it has been shown that the mortality of patients with thrombocytopenia is higher than those without it [Ferrera 2015]. In addition, the effects of $\mathrm{RDW}$, another laboratory finding, on prognosis in IE patients, were previously reported in a single-center study showing that higher RDW is associated with higher mortality rates and provides valuable prognostic information about prognosis [Guray 2014]. RDW is a novel biomarker that recent studies showed the value of predicting adverse outcomes in a wide spectrum of diseases, including sepsis and cardiovascular diseases like heart failure, pulmonary embolism, and acute coronary syndromes [Jo 2013; Aung 2013; Zorlu 2012; Wang 2011]. Another single center study reported baseline RDW and increased rates of RDW was significantly associated with mortality in TAVI patients [Aung 2013]. In our study, RDW was significantly higher in patients with PVE. The severe hemolysis induced by prosthetic valves may increase RDW levels in the nature prognosis of prosthetic valves or serious complications, such as structural deformation, paravalvular leak and excess turbulent flow as a consequence of IE may enhance RDW levels. However, RDW levels were significantly higher in patients with PVE, as analysis did not represent any anticipated mortality difference between the groups.

\section{CONCLUSION}

Although the incidence of PVE is lower than NVE, this rate is increasing day by day with the increase in valve 
surgeries and use of intracardiac devices. Therefore, making the distinction between PVE and NVE is valuable for clinicians, in terms of prognosis and mortality. Although we found higher mean age, HT, AF and RDW rates compared with NVE in our study, we did not find a significant difference in mortality and morbidity. Clinicians should be prepared for septic shock, which is another result of our study, which is a fatal complication with a higher rate in patients with PVE.

\section{REFERENCES}

Aung N, Ling HZ, Cheng AS, Aggarwal S, Flint J, Mendonca M, Rashid M, Kang S, Weissert S, Coats CJ, Richards T, Thomas M, Woldman S, Okonko DO. 2013. Expansion of the red cell distribution width and evolving iron deficiency as predictors of poor outcome in chronic heart failure. Int J Cardiol. Oct 3;168(3):1997-2002.

Baddour LM, Wilson WR, Bayer AS, et al. 2015. Infective endocarditis in adults: diagnosis, antimicrobial therapy, and management of complications: a scientific statement for healthcare professionals from the American Heart Association. Circulation. 132(15): 1435-86.

Bor DH, Woolhandler S, Nardin R, Brusch J, Himmelstein DU. 2013. Infective endocarditis in the U.S., 1998-2009: a nationwide study. PLoS One. 8(3):e60033.

Cahill TJ, Prendergast BD. 2016. Infective endocarditis. Lancet. Feb 27;387(10021):882-93.

Durante-Mangoni E, Bradley S, Selton-Suty C, Tripodi MF, Barsic B, Bouza E, Cabell CH, Ramos AI, Fowler V Jr, Hoen B, Koneçny P, Moreno A, Murdoch D, Pappas P, Sexton DJ, Spelman D, Tattevin P, Miró JM, van der Meer JT, Utili R. 2008. International Collaboration on Endocarditis Prospective Cohort Study Group. Current features of infective endocarditis in elderly patients: results of the International Collaboration on Endocarditis Prospective Cohort Study. Arch Intern Med. Oct 27;168(19):2095-103.

Erbay AR, Erbay A, Canga A, Keskin G, Sen N, Atak R, Demir AD, Balbay Y, Duru E. 2010. Risk factors for in-hospital mortality in infective endocarditis: five years' experience at a tertiary care hospital in Turkey. J Heart Valve Dis. Mar;19(2):216-24.

Ferrera C, Vilacosta I, Fernández C, López J, Sarriá C, Olmos C, et al. 2015. Usefulness of thrombocytopenia at admission as a prognostic marker in native valve left-sided infective endocarditis. Am J Cardiol. 115(7):950-5.

Gomes A, Glaudemans AWJM, Touw DJ, van Melle JP, Willems TP, Maass AH, Natour E, Prakken NHJ, Borra RJH, van Geel PP, Slart RHJA, van Assen S, Sinha B. 2017. Diagnostic value of imaging in infective endocarditis: a systematic review. Lancet Infect Dis. Jan;17(1):e1-e14.

Guray Y, Ipek EG, Guray U, Demirkan B, Kafes H, Asarcikli LD, Cabuk G, Yilmaz MB. 2014. Red cell distribution width predicts mortality in infective endocarditis. Arch Cardiovasc Dis. May;107(5):299-307.

Habib G, Lancellotti P, Antunes MJ, Bongiorni MG, Casalta JP, Del Zotti F, Dulgheru R, El Khoury G, Erba PA, Iung B, Miro JM, Mulder BJ, Plonska-Gosciniak E, Price S, Roos-Hesselink J, Snygg-Martin U, Thuny F, Tornos Mas P, Vilacosta I, Zamorano JL. 2015. ESC Scientific Document Group. 2015 ESC Guidelines for the management of infective endocarditis: The Task Force for the Management of Infective Endocarditis of the European Society of Cardiology (ESC). Endorsed by: European Association for Cardio-Thoracic Surgery (EACTS), the European Association of Nuclear Medicine (EANM). Eur Heart J. Nov
21;36(44):3075-3128.

Hasbun R, Vikram HR, Barakat LA, Buenconsejo J, Quagliarello VJ. 2003. Complicated left-sided native valve endocarditis. Risk classification for mortality. JAMA. 2003;289(15):1933-40.

Granowitz E, Longworth DL. Risk stratification and bedside prognostication in infective endocarditis. JAMA. 289(15):1991-3.

Horstkotte D, Follath F, Gutschik E, Lengyel M, Oto A, Pavie A, SolerSoler J, Thiene G, von Graevenitz A, Priori SG, Garcia MA, Blanc JJ, Budaj A, Cowie M, Dean V, Deckers J, Fernández Burgos E, Lekakis J, Lindahl B, Mazzotta G, Morais J, Oto A, Smiseth OA, Lekakis J, Vahanian A, Delahaye F, Parkhomenko A, Filipatos G, Aldershvile J, Vardas P. 2004. Task Force Members on Infective Endocarditis of the European Society of Cardiology; ESC Committee for Practice Guidelines (CPG); Document Reviewers. Guidelines on prevention, diagnosis and treatment of infective endocarditis executive summary; the task force on infective endocarditis of the European society of cardiology. Eur Heart J. Feb;25(3):267-76.

Jo YH, Kim K, Lee JH, Kang C, Kim T, Park HM, Kang KW, Kim J, Rhee JE. 2013. Red cell distribution width is a prognostic factor in severe sepsis and septic shock. Am J Emerg Med. Mar;31(3):545-8.

Lancellotti P, Moura L, Pierard LA, Agricola E, Popescu BA, Tribouilloy C, Hagendorff A, Monin JL, Badano L, Zamorano JL. 2010. European Association of Echocardiography. European Association of Echocardiography recommendations for the assessment of valvular regurgitation. Part 2: mitral and tricuspid regurgitation (native valve disease). Eur J Echocardiogr. May;11(4):307-32.

Leone S, Ravasio V, Durante-Mangoni E, Crapis M, Carosi G, Scotton PG, Barzaghi N, Falcone M, Chinello P, Pasticci MB, Grossi P, Utili R, Viale P, Rizzi M, Suter F. 2012. Epidemiology, characteristics, and outcome of infective endocarditis in Italy: the Italian Study on Endocarditis. Infection. Oct;40(5):527-35.

Li JS, Sexton DJ, Mick N, Nettles R, Fowler VG Jr, Ryan T, Bashore T, Corey GR. 2000. Proposed modifications to the Duke criteria for the diagnosis of infective endocarditis. Clin Infect Dis. Apr;30(4):633-8.

Loupa C, Mavroidi N, Boutsikakis I, Paniara O, Deligarou O, Manoli H, Saroglou G. 2004. Infective endocarditis in Greece: a changing profile. Epidemiological, microbiological and therapeutic data. Clin Microbiol Infect. Jun;10(6):556-61.

Marques A, Cruz I, Caldeira D, Alegria S, Gomes AC, Broa AL, João I, Pereira H. 2020. Risk Factors for In-Hospital Mortality in Infective Endocarditis. Arq Bras Cardiol. Jan;114(1):1-8.

Murdoch DR, Corey GR, Hoen B, Miró JM, Fowler VG Jr, Bayer AS, Karchmer AW, Olaison L, Pappas PA, Moreillon P, Chambers ST, Chu VH, Falcó V, Holland DJ, Jones P, Klein JL, Raymond NJ, Read KM, Tripodi MF, Utili R, Wang A, Woods CW, Cabell CH. 2009. International Collaboration on Endocarditis-Prospective Cohort Study (ICEPCS) Investigators. Clinical presentation, etiology, and outcome of infective endocarditis in the 21st century: the International Collaboration on Endocarditis-Prospective Cohort Study. Arch Intern Med. Mar 9;169(5):463-73.

Nunes MC, Gelape CL, Ferrari TC. 2010. Profile of infective endocarditis at a tertiary care center in Brazil during a seven-year period: prognostic factors and in-hospital outcome. Int J Infect Dis. May;14(5):e394-8.

Olmos C, Vilacosta I, Fernández C, López J, Sarriá C, Ferrera C, Revilla A, Silva J, Vivas D, González I, San Román JA. 2013. Contemporary epidemiology and prognosis of septic shock in infective endocarditis, European Heart Journal. 34(26):1999-2006. 
San Román JA, López J, Vilacosta I, Luaces M, Sarriá C, Revilla A, et al. 2007. Prognostic stratification of patients with left-sided endocarditis determined at admission. Am J Med. 120(4):369.e1-7.

Schulz R, Werner GS, Fuchs JB, Andreas S, Prange H, Ruschewski W, Kreuzer H. 1996. Clinical outcome and echocardiographic findings of native and prosthetic valve endocarditis in the 1990's. Eur Heart J. Feb;17(2):281-8.

Selton-Suty C, Célard M, Le Moing V, Doco-Lecompte T, Chirouze C, Iung B, Strady C, Revest M, Vandenesch F, Bouvet A, Delahaye F, Alla F, Duval X, Hoen B. 2012. AEPEI Study Group. Preeminence of Staphylococcus aureus in infective endocarditis: a 1-year population-based survey. Clin Infect Dis. May;54(9):1230-9.

Şimşek-Yavuz S, Akar AR, Aydoğdu S, et al. 2019. [Diagnosis, treatment and prevention of infective endocarditis: Turkish consensus report]. Klimik Derg. 32(Suppl. 1): 2-116. Turkish.

Tuğcu A, Yildirimtürk O, Baytaroğlu C, Kurtoğlu H, Köse O, Sener M,
Aytekin S. 2009. Clinical spectrum, presentation, and risk factors for mortality in infective endocarditis: a review of 68 cases at a tertiary care center in Turkey. Turk Kardiyol Dern Ars. Jan;37(1):9-18.

Wang YL, Hua Q, Bai CR, Tang Q. 2011. Relationship between red cell distribution width and short-term outcomes in acute coronary syndrome in a Chinese population. Intern Med. 50(24):2941-5.

Werdan K, Dietz S, Löffler B, et al. 2014. Mechanisms of infective endocarditis: pathogen-host interaction and risk states. Nat Rev Cardiol. 11, $35-50$.

Zoghbi WA. 2010. New recommendations for evaluation of prosthetic valves with echocardiography and doppler ultrasound. Methodist Debakey Cardiovasc J. Jan-Mar;6(1):20-6.

Zorlu A, Bektasoglu G, Guven FM, Dogan OT, Gucuk E, Ege MR, Altay H, Cinar Z, Tandogan I, Yilmaz MB. 2012. Usefulness of admission red cell distribution width as a predictor of early mortality in patients with acute pulmonary embolism. Am J Cardiol. Jan 1;109(1):128-34. 